\title{
Rani rezultati ugradnje umjetnog meniska koljenskog zgloba
}

\section{Early outcome after knee meniscal scaffold implantation}

\author{
Denis Tršek*, Miroslav Hašpl, Dražen Lovrić, Borna Strahonja
}

\begin{abstract}
Sažetak. Cilj: Prikazati operacijsku tehniku i procijeniti rane poslijeoperacijske rezultate ugradnje umjetnog meniska koljenskog zgloba. Ispitanici i metode: $U$ vremenskom razdoblju od 2016. do 2020. godine u specijalnoj bolnici za ortopediju i traumatologiju Akromion izvedeno je devet implantacija umjetnog meniska Actifit u koljenski zglob, kod devet pacijenata. Analiza rezultata liječenja izvršena je kod sedam pacijenata, medijana životne dobi 39 (IQR 10,5) godina. Medijan praćenja bio je 25 (IQR 28.5) mjeseci. Prije operacijskog zahvata i na kraju praćenja izvršili smo funkcionalno testiranje pomoću Lysholm, Tegner i VAS upitnika. Pacijenti su podvrgnuti MR praćenju nakon 3, 6, 12, 24 i 30 mjeseci operacije. Implantat meniska je praćen po Genovese upitniku. Rezultati: Medijan Lysholm upitnika prije ugradnje umjetnog meniska bio je 61 (IQR 10,0), a nakon ugradnje 90 (IQR 5) ( $p=0,011)$. Medijan Tegner funkcionalnog upitnika bio je prije operacije 4 (IQR 0,5), dok je nakon ugradnje umjetnog meniska rezultat porastao na $5($ IQR 1,0$)(p=0,059)$. Medijan VAS upitnika prije operacije bio je 3 (IQR 1,0$)$, a nakon operacije $8($ IQR 0,05$)(p=0,011)$. Šest $(86 \%)$ pacijenata nakon tri mjeseca je pokazalo srednju ekstruziju (Genovese upitnik 2. stupanj) bez daljnje progresije. Analizom MR-a dokazali smo revaskularizaciju meniscealnog presatka uz gubitak morfologije i volumena kao i ekstruziju implantata. Zaključak: Nakon ugradnje umjetnog meniska i relativno kratkog praćenja, do sada nismo evidentirali pogoršanje hondralnog oštećenja femorotibijalnog zgloba, dok su istovremeno znatno poboljšani funkcionalni rezultati.
\end{abstract}

Ključne riječi: magnetska rezonancija; menisk; popravak meniska; transplantacija meniska; umjetni menisk

Abstract. Aim: The aim of the study was to demonstrate a surgical technique and evaluate the early outcome of a knee joint meniscal scaffold implantation. Patients and methods: During the time period between years 2016 and 2020, in our hospital nine Actifit meniscal scaffolds were implanted into the knee joint of nine different patients. The treatment outcome analysis was performed in 7 patients with the median age of 36 (IQR 10.5) years. The median follow-up was 25 (IQR 28.5) months. Before the surgery, and at the end of the study, functional testing was performed using Lysholm, Tegner and VAS questionnaires. All patients underwent MRI checkups at 3, 6, 12, 24 and 30 months after the surgery. Meniscal implants were evaluated using the criteria of Genovese. Results: The median Lysholm score before the meniscal scaffold implantation was 61 (IQR 10), and after it was 90 (IQR 13.0) $(p=0.011)$. The median Tegner functional questionnaire score before the meniscal scaffold implantation was 4 (IQR 0.5), while after the surgery score went up to 5 (IQR 0.5) $(p=0.059$ ). The median preoperative VAS score was 3 (IQR 1.0), and the postoperative score was 8 (IQR $0.5)(p=0.011)$. At 3 months follow-up, $6(86 \%)$ patients showed a moderate meniscal extrusion (Genovese type 2), with no further progression. The MRI analysis showed the meniscal scaffold vascularization, even with the loss of morphology and volume as well as implant extrusion. Conclusion: In short follow-up after the meniscal scaffold implantation, till now there has been no progression found of chondral damage in femorotibial joint, with concurrent significant functional improvement.

Key words: magnetic resonance; meniscus; meniscal repair; meniscal scaffold; meniscal transplant
„Akromion“, Specijalna bolnica za ortopediju i traumatologiju, Krapinske Toplice

http://hrcak.srce.hr/medicina 


\section{UVOD}

Uloga meniska iznimno je važna za očuvanje hrskavičnog pokrova i funkcije koljena, tj. sprječavanja ili usporavanja nastanka osteoartritisa ${ }^{1-12}$. Meniscektomijom se ubrzava gubitak hrskavice. Potpuno uklanjanje medijalnog meniska rezultira smanjenjem kontaktne površine femorotibijalnog zgloba za 50 do $70 \%$ i povećanjem opterećenja na mjestu kontakta za $100 \%$. Potpuna lateralna meniscektomija uzrokuje 40 do $50 \%$ manju kon-

Nedostatak meniska nakon meniscektomije ili nakon neuspjelog šivanja meniska možemo nadoknaditi ugradnjom umjetnog meniska i time usporiti ili spriječiti napredovanje osteoartritisa.

taktnu površinu i čak 200 do $300 \%$ veće opterećenje na mjestu kontakta ${ }^{13,14}$ (slika 1$)$. Kako bi se sačuvao menisk, razvile su se metode šivanja rupture koje su pokazale znatno bolje rezultate $u$ očuvanju hrskavice nego meniscektomije ${ }^{15}$ i velik postotak uspješnosti cijeljenja meniska, između 70 i $90 \%{ }^{16-18}$.

Od svih lezija meniska, samo $15 \%$ je pogodno za šivanje. Danas, napretkom tehnika šivanja i instrumentarija, taj postotak svakim danom raste, ali još uvijek značajan postotak oštećenih meniska nije pogodan za šivanje te je potrebna meniscektomija. Nedostatak meniska nakon meniscektomije možemo nadoknaditi transplantacijom homolo-

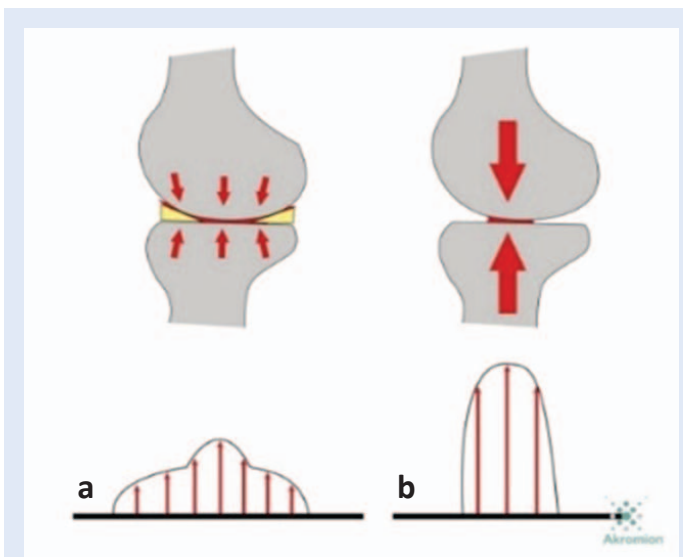

Slika 1. Smanjenje kontaktne površine i povećanje opterećenja na mjestu kontakta između dvaju kondila nakon meniscektomije. Koljeno prije (a) i poslije (b) mensicektomije. gnog presatka ili umjetnog meniska. Ugradnja umjetnog meniska (slika 2) ima više prednosti u odnosu na transplantaciju homolognog presat$k a^{19,20}$. Odnosi se na mogućnost nadoknade različitih veličina defekata meniska, manje je zahtjevna operativna tehnika, a implantat je mnogo dostupniji u usporedbi s kompleksnom tehničkom i pravnom procedurom nabave homolognog transplantata meniska. Operativne komplikacije i reoperacije znatno su rjeđe, a implantat ne izaziva imunološke ili upalne reakcije. Stoga danas sve više raste broj ugrađenih umjetnih meniska.

Na tržištu su danas dostupne tri vrste umjetnog meniska. Po broju ugrađenih implantata najčešći je Menaflex Collagen Meniscal Implant, CMI (Ivy Sports Medicine, Gräfelfing, Germany). Nakon

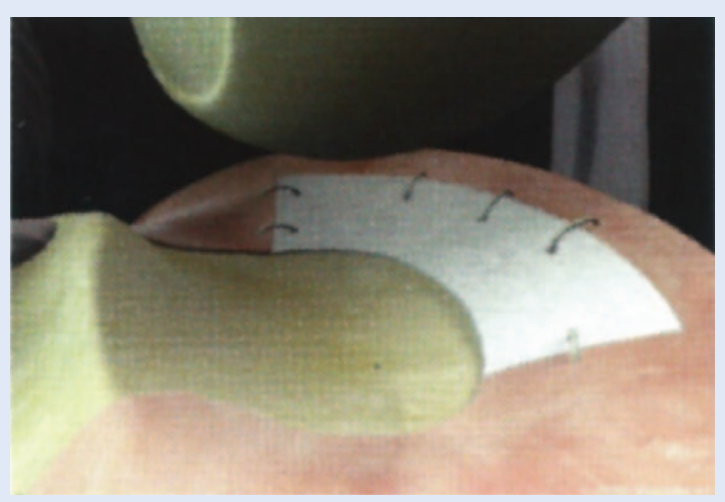

Slika 2. Shematski prikaz implantacije biorazgradivog nosača Actifita na mjesto defekta meniska. (Orteq Sports Medicine, London, UK).

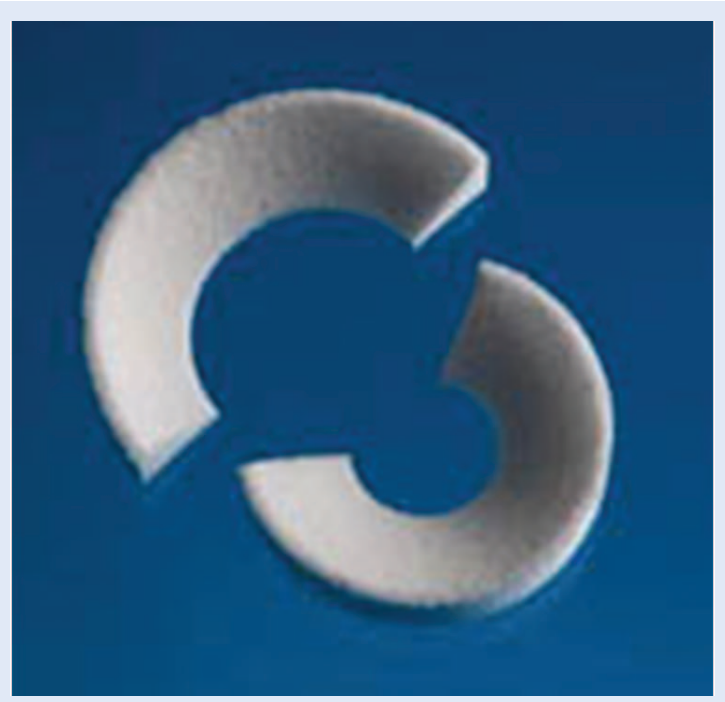

Slika 3. Razlika u obliku lateralnog i medijalnog Actifita (Orteq Sports Medicine, London, UK). 
toga slijedi sve veći broj ugrađenih Actifit $^{\circledR}$ scaffold (Orteq Sports Medicine, London, UK). Treći po redu je NUsurface ${ }^{\circledR}$ Meniscus Implant (Active Implants LLC, Memphis, Tennessee, US) koji svojom građom ne prati prirodni oblik meniska, nego je u obliku okruglog jastuka koji se umeće između natkoljenice i potkoljenice te nije potrebna fiksacija.

U našoj bolnici svim pacijentima je ugrađen Actifit $^{\circledR}$ scaffold. Svojim oblikom prati anatomske karakteristike medijalnog i lateralnog meniska, pa je tako medijalni manjeg polumjera i širi, dok je lateralni većeg polumjera i uži (slika 3). Actifit je implantacijski nosač u obliku saća (slika 4), međusobno povezanih biokompatibilnim i vrlo sporo biorazgradivim polimerima $s$ velikim brojem pora. Zbog svoje građe ima veliku sposobnost vaskularizacije ili urastanja tkiva meniska (slika 5). CMI je građen od kolagenih niti i zato nešto kompaktnije, čvršće građe te nešto teži za rukovanje prilikom ugradnje i ima brže vrijeme razgradnje od Actifita ${ }^{21,22}$

Pregledom literature u kojoj su uspoređivani rezultati obaju implantata pokazalo se da oba pokazuju bolje rezultate ako su ugrađeni uz dodatne operacije rekonstrukcije prednje ukrižene sveze ili korektivne osteotomije proksimalne tibije ${ }^{23}$, a ujedno su to i najčešći dodatni kirurški zahvati koje se izvode zajedno s ugradnjom umjetnog meniska ${ }^{24}$.

Kako svaka lezija meniska nije pogodna za šivanje, tako i svako koljeno, odnosno pacijent, nije kandidat za ugradnju umjetnog meniska. Da bi rezultati bili što bolji, trebamo što više poštovati indikacije za ugradnju umjetnog meniska. Idealni kandidat za ugradnju umjetnog meniska je pacijent između 18 i 55 godina kojem je učinjena manja ili veća djelomična meniscektomija. Mora biti sačuvan prednji i stražnji rog meniska kako bi se umjetni menisk imao za što fiksirati. Periferni dio meniska, odnosno baza meniska prema čahuri zgloba, mora biti sačuvana radi sprječavanja naknadne ekstruzije implantata. Po ICRS klasifikaciji najpogodnija su oštećenja hrskavice do drugog stupnja. Koljeno mora biti stabilno ili se ugradnja umjetnog meniska mora učiniti zajedno s rekonstrukcijom prednje, odnosno stražnje ukrižene sveze. Koljeno mora biti uredne osovine, a pacijen-

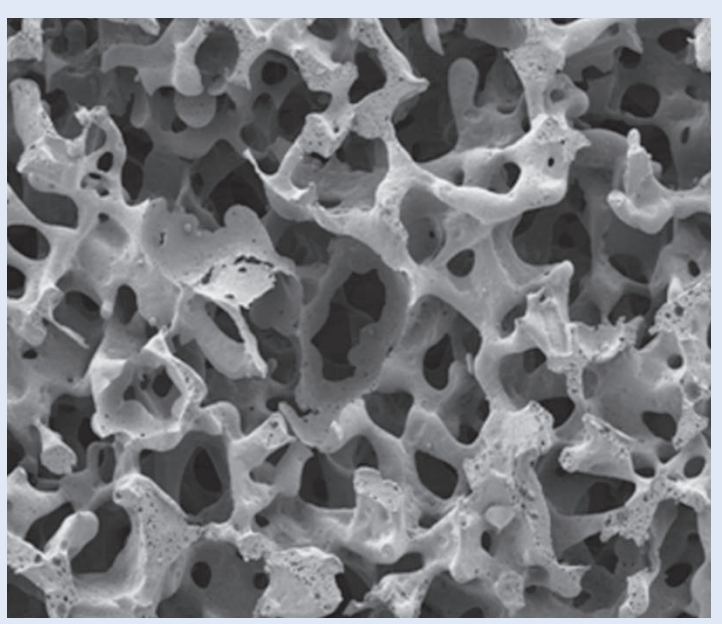

Slika 4. Građa Actifita u obliku saća (Orteq Sports Medicine, London, UK).

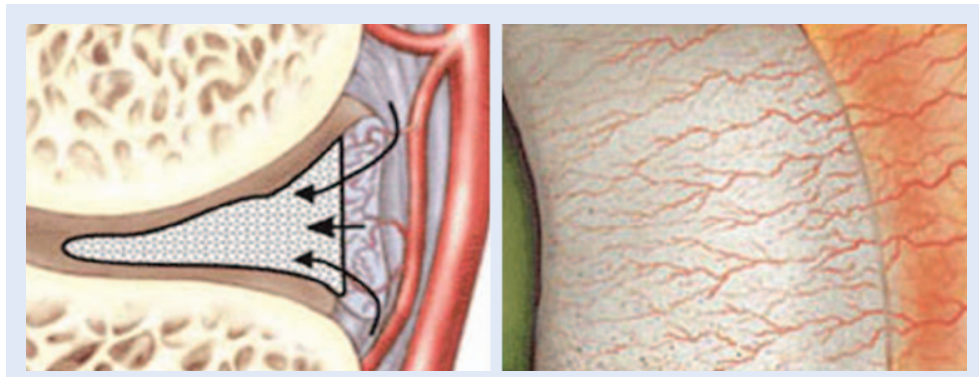

Slika 5. Urastanje krvnih žila u biorazgradivi nosač Actifit (Orteq Sports Medicine, London, UK).

ti ne smiju biti pretili, uz BMI ne veći od $35 \mathrm{~kg} / \mathrm{m}^{2}$. Jedna od učestalijih komplikacija ugradnje umjetnog meniska je ekstruzija tijela implantata prema čahuri zgloba ${ }^{25}$, do koje dolazi ako se prilikom meniscektomije odstrani cijela baza meniska sve do čahure zgloba.

\section{OPERACIJSKA TEHNIKA UGRADNJE UMJETNOG MENISKA}

Ugradnja umjetnog meniska u potpunosti se izvodi artroskopskom tehnikom, uz standardni anterolateralni i anteromedijalni portal, koristeći standardni artroskopski instrumentarij za pripremu ležišta za umjetni menisk ${ }^{26}$.

Prilikom pripreme ležišta vrlo bitno je učiniti revaskularizaciju uz pomoć rašpe ili trepanaciju običnom iglom. Pri tome treba paziti da se ostavi baza meniska, čime se prevenira naknadna ekstruzija implantata. Specijalnim instrumentarijem, koji dolazi zajedno u pakiranju s implantatom (slika 6), izmjeri se defekt meniska, odnosno 

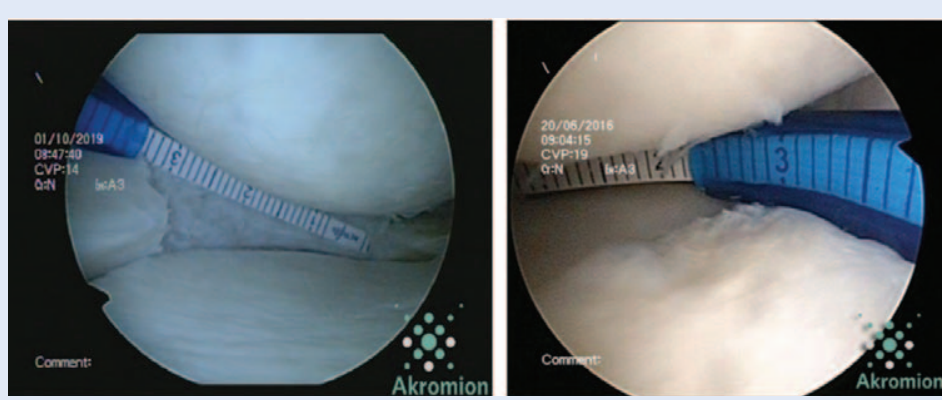

Slika 6. Izmjera veličine defekta meniska.
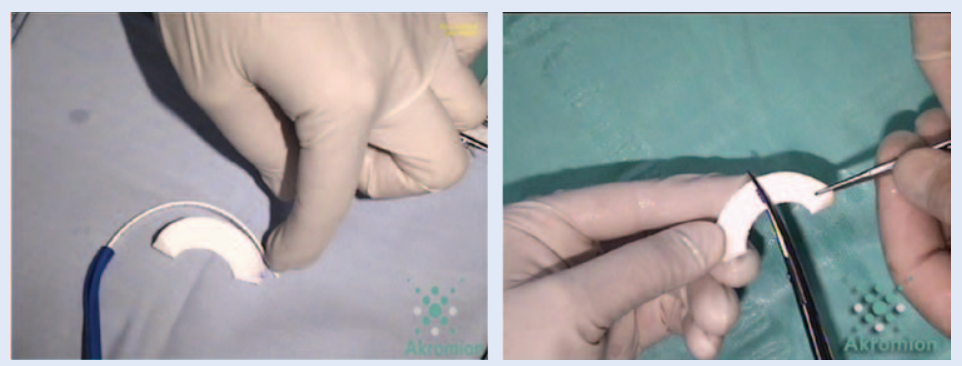

Slika 7. Rezanje umjetnog meniska prema izmjerenom defektu meniska.
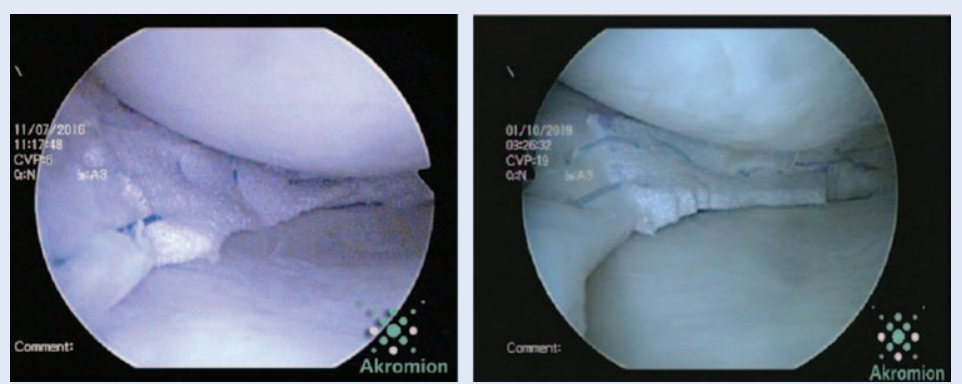

Slike 8. Stanje nakon fiksacije umjetnog meniska na mjestu defekta trupa i stražnjeg roga medijalnog meniska.

veličina ležišta. Prilikom rezanja umjetnog meniska (slika 7) dobro je dodati 10 posto na izmjerenu vrijednost, kako bismo izbjegli preveliku napetost implantata prilikom fiksacije. Prilikom fiksacije umjetnog meniska koristimo se svim tehnikama šivanja kao i kod šivanja rupture meniska, koristeći specijalni instrumentarij za svaku pojedinu tehniku (slika 8).

Izvana-unutra (outside-in) tehniku koristimo za spajanje implantata s prednjim rogom meniska. Iznutra-van (inside-out) tehniku koristimo za fiksaciju trupa implantata za bazu meniska, odnosno čahuru zgloba. Za tehniku sve-unutra (all inside) u našoj bolnici koristimo Omnispan i Truespan (DePuy Mitek Sports Medicine, Johnson\&Johnson) instrument kojim fiksiramo implantat za stražnji korijen meniska i stražnju ča- huru zgloba. Kao i kod šivanja meniska, kod fiksacije umjetnog meniska bitno je rekonstruirati što veću kontaktnu površinu između baze umjetnog meniska i ostatnog dijela baze meniska, odnosno čahure zgloba. To postižemo tako da provlačimo šave i kroz donju površinu umjetnog meniska, a ne samo kroz gornju površinu.

Pri šivanju meniska, zbog njegove građe i uzdužnog rasporeda kolagenih niti, dokazano je da su poprečne šavi puno čvršće nego uzdužne ${ }^{27,28}$. Kod fiksacije umjetnog meniska, gdje zbog građe umjetnog meniska u obliku saća nema prijenosa sila uzduž kolagenih niti kao u prirodnom menisku, dokazano je suprotno. Uzdužne šavi su čvršće od poprečnih. Dokazano je i da se PDS koncem može postići veća sila fiksacije nego Ethibond 0 koncem ${ }^{29}$.

Koristili smo FiberWire (Arthrex) neresorptivni konac, s obzirom na to da smo kod šivanja rupture meniska sa PDS koncem primijetili pojavu subkutanih seroma prilikom resorpcije navedenog konca, a što je poznata komplikacija ${ }^{18}$. Prilikom fiksacije umjetnog meniska potrebno je paziti na sile zatezanja pri postavljanju šavi. One moraju biti puno manje nego kod zatezanja šavi prilikom šivanja rupture meniska. Zbog krhke građe u obliku saća, sile pri kojima dolazi do oštećenja umjetnog meniska su već od 50 N, za razliku od šivanja meniska gdje sile zatezanja mogu ići od 130 pa čak i do $175 \mathrm{~N}^{29}$. Ovaj podatak je vrlo bitan, ne samo zato što se oštećuje struktura umjetnog meniska, nego i direktno utječe na njegovu vaskularizaciju, odnosno integraciju.

Što se tiče pozicioniranja šavi duž umjetnog meniska, vodimo se iskustvom stečenim šivanjem rupture meniska. Ako usporedimo šivanje medijalnog i lateralnog meniska, dokazano je da je broj reoperacija manji kod lateralnog meniska ${ }^{17}$. To se objašnjava time što je medijalni (sašiveni) menisk više fiksiran na zglobnu čahuru i time mu je ograničen fiziološki pokret po platou tibije. Lateralni menisk je mobilniji i zato je kod njegova šivanja jako bitno fiksirati leziju uz održanje mobilnosti. Isto tako, kod fiksacije lateralnog umjetnog meniska hijatus treba ostaviti slobodan i tako oponašati anatomiju i biomehaniku prirodnog lateralnog meniska. 


\section{REHABILITACIJA NAKON UGRADNJE} UMJETNOG MENISKA

Ugradnja umjetnog meniska izvodi se ambulantno kao dnevna kirurgija. Pacijent nekoliko sati iza operacije ustaje iz kreveta uz imobilizaciju koljenskom ortozom i hoda uz minimalno opterećenje operirane noge, do $5 \mathrm{~kg}$ tjelesne mase. Nakon četvrtog poslijeoperacijskog tjedna, postepeno se povećava opterećenje noge, dodavajući svakih 7 dana po $10 \mathrm{~kg}$. Puno opterećenje i hod bez pomagala dozvoljava se deveti tjedan iza operacije. Pacijent nosi ortozu sa zglobom uz ograničenje fleksije prvih 6 do 8 tjedana iza operacije, ovisno o svojoj težini. Do kraja drugog tjedna dozvoljena je fleksija do 30 stupnjeva, do kraja četvrtog tjedna do 60 stupnjeva, a nakon punih šest tjedana dopušta se fleksija veća od 90 stupnjeva.

\section{ISPITANICI I METODE}

Od 2016. do 2020. godine u specijalnoj bolnici za ortopediju i traumatologiju „Akromion“ izvedeno je 9 ugradnji umjetnog meniska Actifit (Orteq Sports Medicine, London, UK) kod istog broja pacijenata. Dva pacijenta nisu uključena u istraživanje zbog kratkog vremena praćenja.

Svi pacijenti prije operacijskog zahvata ponaosob su potpisali informirani pristanak u kojem su upoznati sa svojim sadašnjim zdravstvenim stanjem, operacijskom procedurom, općim i osobitim rizicima operacijskog zahvata, vrstom anestezije, poslijeoperacijskim praćenjem kao i načinom rehabilitacije.

Svaki pacijent je svojim potpisom potvrdio pristanak na operacijski zahvat. Sve je provedeno prema pravilima zaštite privatnosti i povjerljivosti medicinskih podataka.

Provedena je prospektivna studija kod 7 pacijenata, 5 (71 \%) muških i 2 (29\%) ženska, s prosječnom životnom dobi od 36 (medijan 39, IQR 10,5) godina. Ugrađena su 4 (57\%) medijalna i 3 (43\%) lateralna meniska. Kod 6 (86\%) pacijenata prije zahvata izvedena je meniscektomija, dok je kod 1 (14 \%) pacijenta menisk šivan, a budući da ruptura nije sanirala, indicirana je meniscektomija i ugradnja umjetnog meniska u jednom aktu. Kod 2 (28\%) pacijenta hrskavični pokrov je bio kompletno očuvan, kod 1 (14\%) smo našli oštećenje hrskavice 1 . stupnja, kod 2 (28\%) 2. stupnja i kod još 2 (28 \%) 4. stupnja oštećenja po ICRS-u. Isto-

Ugradnja umjetnog meniska sve više zamjenjuje transplantaciju meniska. Prednost ugradnje umjetnog meniska je njezina dostupnost i mogućnost nadoknade različitih veličina defekata. Tehničke pogreške i reoperacije puno su rjeđe. Nisu primijećene imunološke ili upalne reakcije.

vremeno, kao pridruženi operacijski zahvat, kod 2 pacijenta učinjene su mikrofrakture, kod 2 šivanje drugog meniska, a kod jednog korektivna valgizacijska osteotomija proksimalne tibije. Prosječna dužina defekta meniska bila je $46 \mathrm{~mm}$ (medijan 45, IQR 10,0). Broj šavova u prosjeku je bio 7,6 (medijan 7, IQR 1,5). Kod jednog pacijenta učinjena je kontrolna artroskopija (second-look) koljena 3 mjeseca nakon operacije zbog bolova i sumnje na oštećenje implantata prema MR analizi. Vrijeme praćenja bilo je 23 (medijan 25, IQR 28,5) mjeseca (tablica 1).

Pacijenti su praćeni prospektivno redovitim ambulantnim kontrolama nakon 1, 3, 6 i 12 mjeseci, a na kraju je izvršeno funkcionalno testiranje prema Lysholm, Tegner i VAS upitniku. Istovjetno testiranje provedeno je i prije operacijskog zahvata. Svi su pacijenti podvrgnuti MR praćenju 3, 6, 12, 24 i 30 mjeseci nakon operacije. Učinjena je analiza hrskavice i klasifikacija po ICRS-u, a implantat

Tablica 1. Deskriptivna statistika podataka o ispitanicima $(N=7)$.

\begin{tabular}{|l|c|c|c|c|}
\hline \multicolumn{1}{|c|}{ Varijabla } & Med & IQR & Min & Maks \\
\hline Životna dob (godine) & 39 & 10,5 & 16 & 46 \\
\hline Vrijeme praćenja (mjeseci) & 25 & 28,5 & 6 & 46 \\
\hline Veličina defekta meniska (mm) & 45 & 10,0 & 35 & 60 \\
\hline Broj šavova & 7 & 1,5 & 5 & 10 \\
\hline
\end{tabular}


meniska je praćen po Genovese upitniku i po razvoju ekstruzije ${ }^{30}$.

\section{Statistika}

Statistička analiza podataka sastojala se od deskriptivne $\mathrm{i}$ inferencijalne obrade podataka. U okviru deskriptivne statistike prikazani su medijani, interkvartilni rasponi te minimumi i maksimumi analiziranih varijabli. Razlike u vrijednostima funkcionalnih upitnika prije i nakon operativnog

Implantacija meniska u budućnosti bi mogla ići i u smjeru korištenja faktora rasta koji bi stimulirati staničnu proliferaciju i diferencijaciju kako bi se izazvala reparacija, odnosno regeneracija prirodnog meniska.

Analiza MR-a nakon operacije pokazala je da gubitak morfologije i volumena, kao i ekstruzija implantata, nisu doveli do napredovanja oštećenja hrskavice. zahvata testirane su Wilcoxonovim testom za zavisne uzorke ${ }^{31}$. Značajnost je postavljena na $P<$ 0,05 . Analiza je provedena u statističkom jeziku R. ( $R$ jezik je dostupan kao slobodan softver pod uvjetima Free Software Foundation GNU, https:// www.r-project.org $/{ }^{32}$ ).

\section{REZULTATI}

Medijan Lysholm upitnika prije ugradnje umjetnog meniska iznosio je 61 (IQR 10), a nakon ugradnje 90 (IQR 5) ( $p=0,011)$. Medijan Tegner funkcionalnog upitnika bio je prije operacije 4 (IQR 0,5), dok je nakon ugradnje umjetnog meniska rezultat porastao na 5 (IQR 0,5) ( $p=0,059)$. Medijan VAS upitnika prije operacije bio je 3 (IQR $1,0)$, a nakon operacije 8 (IQR 0,5$)(p=0,011)$ (tablica 2).

Analiza MR-a pokazuje da su svi implantati do 12 mjeseci nakon zahvata bili uredne morfologije i volumena (Genovese upitnik 3. stupanj). Nakon 12 mjeseci kod 5 (71\%) pacijenata dolazi do po-

Tablica 2. Prikaz medijana (Med), interkvartilnih raspona (IQR), minimumi (Min) i maksimumi (Maks) analiziranih varijabli za vrijednosti funkcionalnih upitnika prije i poslije operativnog zahvata te razlika njihovih vrijednosti $\mathrm{i}$ rezultati Wilcoxonova neparametarskog testa za zavisne uzorke

\begin{tabular}{|c|c|c|c|c|c|c|c|}
\hline \multirow{2}{*}{$\begin{array}{l}\text { Upitnik } \\
\text { (Raspon) }\end{array}$} & \multirow{2}{*}{$\begin{array}{c}\text { Prije } \\
\text { operacije } \\
\text { Med } \\
\text { (IQR) }\end{array}$} & \multirow{2}{*}{$\begin{array}{c}\text { Poslije } \\
\text { operacije } \\
\text { Med } \\
\text { (IQR) }\end{array}$} & \multicolumn{3}{|c|}{ Razlika } & \multicolumn{2}{|c|}{$\begin{array}{c}\text { Wilcoxon } \\
\text { test }\end{array}$} \\
\hline & & & $\begin{array}{l}\text { Med } \\
\text { (IQR) }\end{array}$ & Min & Maks & V & p \\
\hline $\begin{array}{l}\text { Lysholm } \\
(0-100)\end{array}$ & $\begin{array}{c}61 \\
(10,0)\end{array}$ & $\begin{array}{c}90 \\
(5,0)\end{array}$ & $\begin{array}{c}30 \\
(13,0)\end{array}$ & 8 & 46 & 28 & 0,011 \\
\hline $\begin{array}{l}\text { Tegner } \\
(0-10)\end{array}$ & $\begin{array}{c}4 \\
(0,5)\end{array}$ & $\begin{array}{c}5 \\
(0,5)\end{array}$ & $\begin{array}{c}1 \\
(1,5)\end{array}$ & 0 & 3 & 10 & 0,049 \\
\hline $\begin{array}{l}\text { VAS } \\
(0-10)\end{array}$ & $\begin{array}{c}3 \\
(1,0)\end{array}$ & $\begin{array}{c}8 \\
(0,5)\end{array}$ & $\begin{array}{c}5 \\
(1,0) \\
\end{array}$ & 3 & 6 & 28 & 0,011 \\
\hline
\end{tabular}

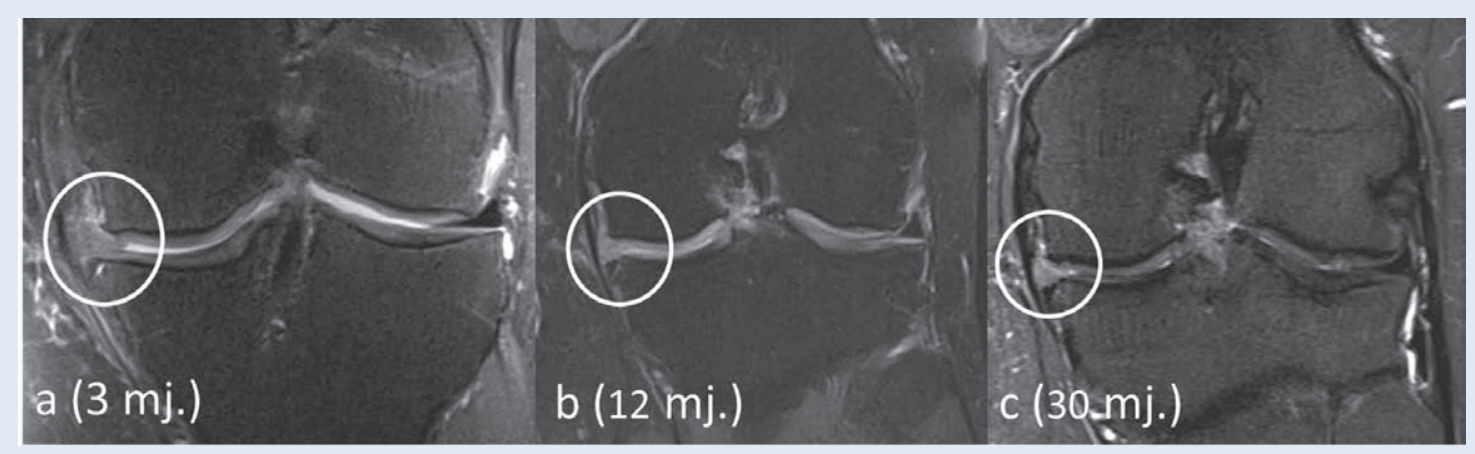

Slika 9. a, b i c) MR presjeci nakon 3, 12 i 30 mjeseci - komparativne slike T2 - weighted fat-suppressed fast spin echo tehnike snimanja (koronarna ravnina): subluksacija umjetnog meniska (bijeli krug) uz smanjenje veličine i snižavanje (degradaciju) intenziteta signala nakon 12 mjeseci. Sličan nalaz nakon 30 mjeseci. 


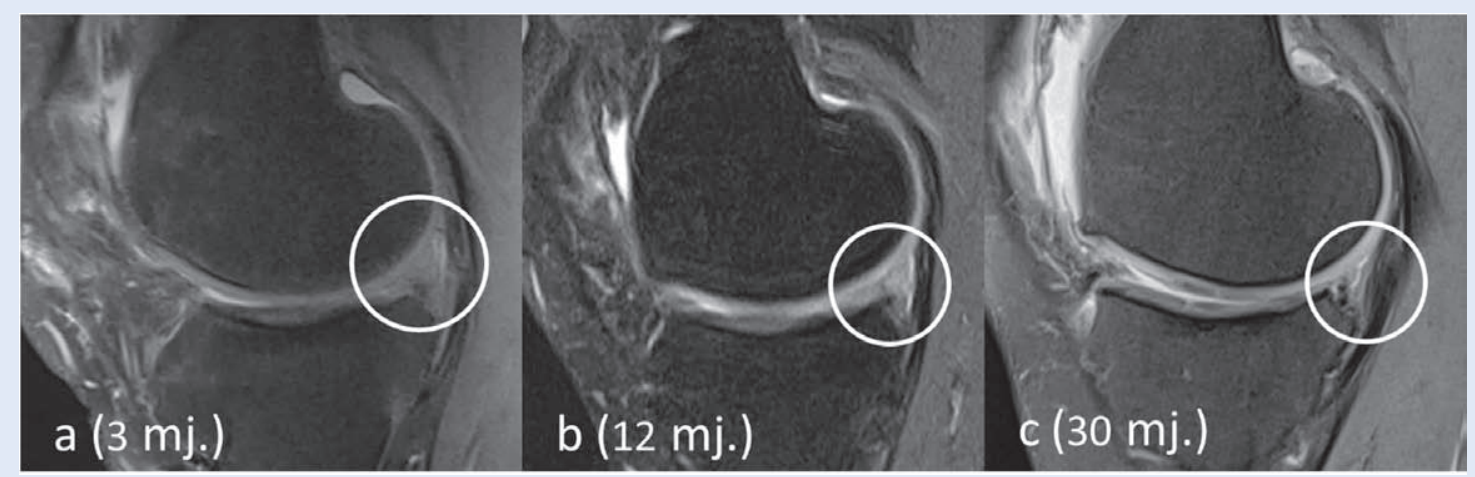

Slika 10. a, b i c) MR presjeci nakon 3, 12 i 30 mjeseci - komparativne slike Proton density-weighted fatsuppressed (PD FS) fast spin echo tehnike snimanja (sagitalna ravnina): zona stražnjeg spoja implantata i prirodnog meniska (posterior interface) sa smanjenjem veličine i sniženjem (degradacijom) intenziteta signala nakon 12 mjeseci. Sličan nalaz nakon 30 mjeseci.

remećaja građe i smanjenja volumena (2. stupanj). Implantat je kod svih pacijenata do 12 mjeseci nakon zahvata pokazivao vrlo visok intenzitet signala (Genovese upitnik 1. stupanj). Kod 4 pacijenta koji su praćeni 12 mjeseci, pokazuje se smanjenje intenziteta signala kao znak proliferacije tkiva prirodnog meniska u sam implantat (Genovese upitnik 2. stupanj).

Kod 2 pacijenta koje smo pratili kroz 30 mjeseci nije došlo do znakova odvajanja implantata od prirodnog meniska. Kod jednog pacijenta je nakon 3 mjeseca došlo do izražene ekstruzije meniska (Genovese upitnik 3. stupanj). Ostalih 6 (86\%) pacijenata nakon 3 mjeseca od operacije pokazalo je srednju ekstruziju (Genovese upitnik 2. stupnja) i do kraja vremena praćenja nisu pokazali daljnje napredovanje ekstruzije (slike 9 i 10).

Edem kosti se unutar 12 mjeseci pokazao kod 3 (43\%) pacijenta, a nakon 12. mjeseca kod sva tri pacijenta edem kosti se povukao. Nismo našli napredovanje oštećenja hrskavice prema ICRS klasifikaciji niti kod jednog pacijenta. Interesantno je da smo kod jednog pacijenta primijetili poboljšanje nalaza hrskavice stražnjeg ruba platoa tibije u zoni implantata meniska sa 3 . stupnja na 2. stupanj (slika 11).

Što se tiče komplikacija, možemo spomenuti da smo kod jedne pacijentice 3 mjeseca nakon operacije zbog manjih bolova pri hodu učinili kontrolnu artroskopiju. Nađeno je uredno preraštanje tkiva meniska u strukturu umjetnog meniska (slike 12 -14).

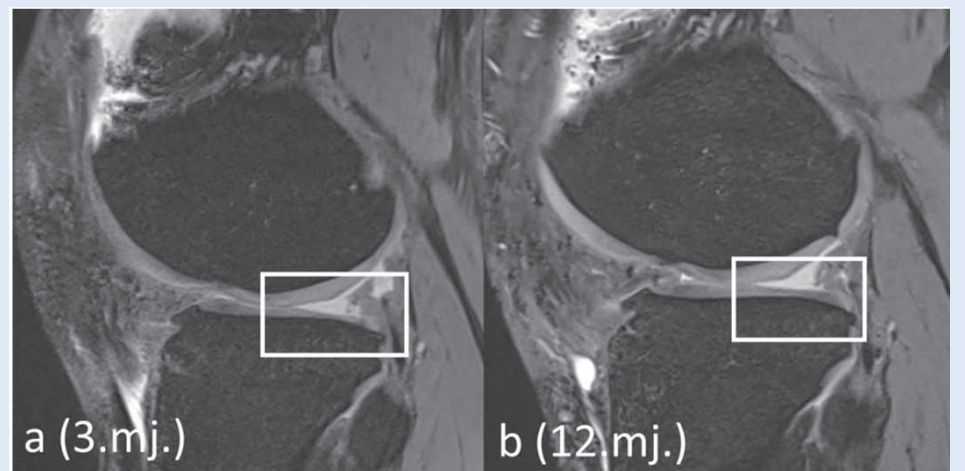

Slika 11. a i b) MR presjeci istog ispitanika nakon 3 i 12 mjeseci komparativne slike T2 TRUFI (True fast imaging) 3D tehnike snimanja (sagitalna ravnina) pokazuju poboljšanje nalaza hrskavice stražnjeg ruba platoa tibije u zoni implantata meniska (bijeli pravokutnik).

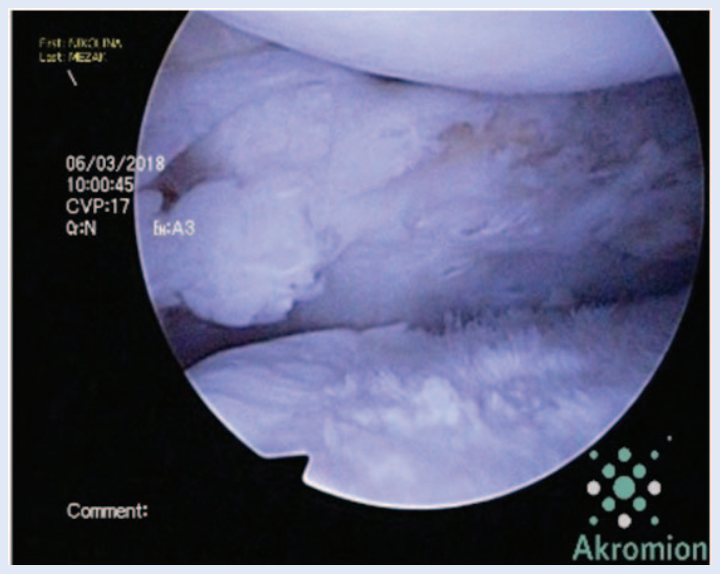

Slika 12. Stanje nakon učinjene meniscektomije lateralnog meniska.

Nakon zahvata, s vremenom praćenja od dvije godine, pacijentica više nije imala bolova niti tegoba s koljenom. 

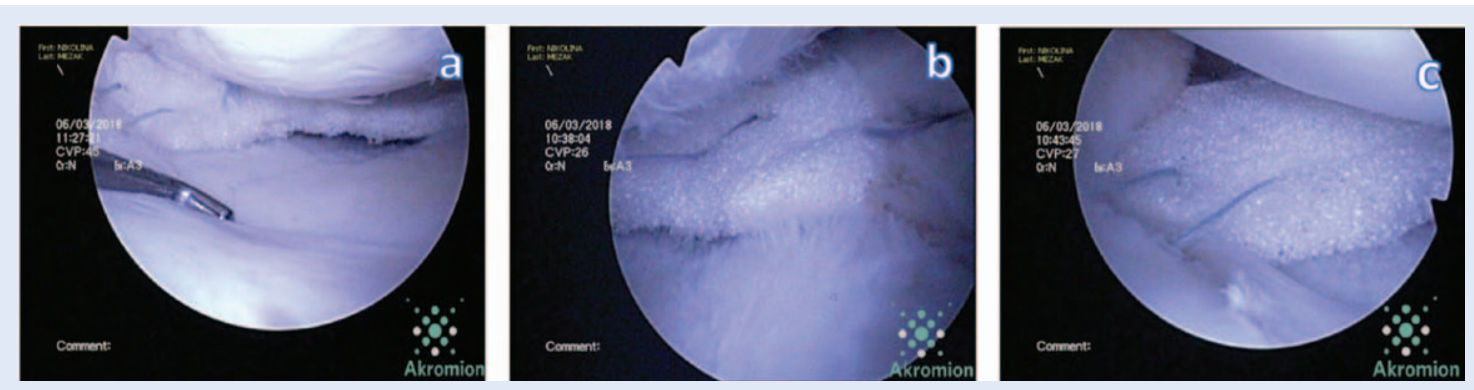

Slika 13. Stanje nakon fiksacije lateralnog umjetnog meniska. a) prednji rog; b) trup; c) stražnji rog.
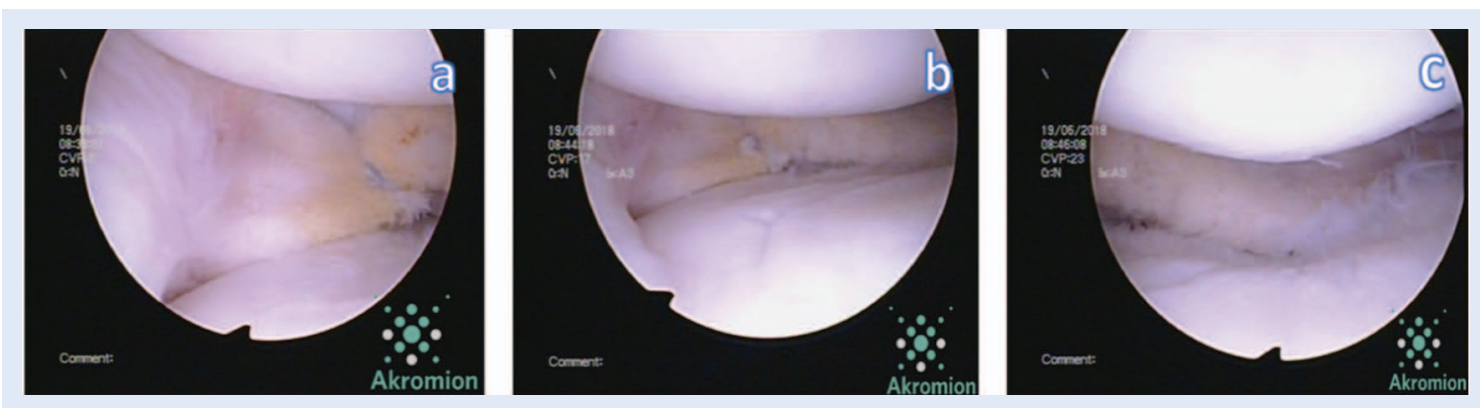

Slika 14. Tri mjeseca nakon ugradnje umjetnog meniska (second-look artroskopija). a) prednji rog; b) trup; c) stražnji rog.

\section{RASPRAVA}

Poteškoća kod šivanja rupture meniska je potreba reoperacije radi nesanirane rupture, koje su pet puta učestalije nego nakon meniscektomija ${ }^{17}$. Paxton i suradnici su dokazali da na uspjeh cijeljenja ponovnog šivanja meniska značajno ne utječe vrsta lezije, je li medijalni ili lateralni menisk, tehnika šivanja niti dodatne operacije. Dokazali su, međutim, da na uspjeh cijeljenja utječe životna dob pacijenta. Kod mlađih pacijenata primijećen je veći postotak necijeljenja ${ }^{33}$. Kod neuspjelog šivanja rupture meniska postavlja se dilema pred kirurga, treba li ponovno šivati takav menisk ili učiniti meniscektomiju, odnosno treba li pristupiti odmah i ugradnji umjetnog meniska. Uspješnost ponovnog šivanja meniska skoro je ista kao i nakon primarnog šivanja i kreće se između 59 i $79 \%^{34,35}$.

Pujol i suradnici ${ }^{36}$ došli su do interesantnog zaključka da volumen naknadne meniscektomije nakon neuspjelog šivanja meniska nije veći u usporedbi s volumenom meniscektomije koja bi bila izvedena da se nije primarno učinilo šivanje meniska. Zato zaključuju da prihvatimo mogući neuspjeh šivanja jer ništa ne gubimo, odnosno, u slučaju rerupture, menisk se može ponovno zašiti. lako su rezultati ponovnog šivanja meniska skoro jednako dobri kao i nakon primarnog šivanja, svejedno se kirurzi vrlo rijetko odlučuju na ponovno šivanje, što nam pokazuje i mali broj studija o tome $33-35,37$.

Nakon meniscektomije ili neuspjelog šivanja meniska indicirana može biti ugradnja umjetnog meniska ili transplantacija meniska. Kao što svako puknuće meniska nije pogodno za šivanje, tako ni svaki defekt meniska nakon učinjene meniscektomije nije za ugradnju umjetnog meniska. Fetzer i suradnici $^{38}$ su analizirali 1014 pacijenata i ustvrdili da su samo $35 \%$ medijalnih i $55 \%$ lateralnih lezija meniska imali jasnu indikaciju za ugradnju umjetnog meniska. Indikacija za transplantaciju homolognog meniska ili ugradnju umjetnog meniska predstavlja stanje u smislu bolova u zglobnoj pukotini nakon meniscektomije, koji pretpostavljaju potencijalno oštećenje hrskavice. Osovina treba biti očuvana kao i ligamentarni aparat.

Ugradnja umjetnog meniska danas sve više zamjenjuje transplantaciju homolognog meniska. Liu i suradnici ${ }^{39}$ pregledom literature ustvrdili su da transplantati meniska mogu odgoditi napredovanje osteoartritisa za ograničeno vremensko razdoblje, ali uz određena ograničenja. Biomeha- 
nička svojstva prirodnog meniska ne mogu se u potpunosti zamijeniti umjetnim meniskom. Kongruencija, fiksacija, biokompatibilnost i potencijalna mogućnost infekcija, kao i ostale perioperacijske komplikacije uvijek će ostati ograničenja za korisnike transplantata.

Pregledom studija ${ }^{19,40-44}$ i usporedbom rezultata transplantacije homolognog meniska s ugradnjom umjetnog meniska, vidi se da je puno veći postotak reoperacija pri transplantaciji meniska $(16,4-46,0 \%)$ nego nakon ugradnje umjetnog meniska (4,2 - 9,5 \%). Veći je postotak nezarastanja, odnosno izostanka revaskularizacije nakon transplantacije meniska (6,3 - 28,6\%), nego nakon ugradnje umjetnog meniska (1,3 - 17,3\%). Mora se uzeti u obzir i da na dobivene vrijednosti može utjecati činjenica što je transplantacija meniska puno starija metoda i zbog toga u većini radova ima duže vrijeme praćenja.

Ako uspoređujemo rezultate između do sada dva najčešće korištena umjetna meniska, Actifit i CMI, Houck i suradnici ${ }^{23}$ su u svojoj analizi kojom su obuhvatili 19 istraživanja sa 658 pacijenata (347 Actifit i 311 CMI) i s prosječnim vremenom praćenja od 45 mjeseci, pokazali da je postotak neuspješnosti za Actifit 9,9 \%, a za CMI 6,7 \%. Pacijenti su u prosjeku bili životne dobi 36 godina. Actifit je bolje rezultate pokazao u KOOS i IKDC upitnicima, a CMI u radiološkoj evaluaciji. Presadak meniska Actifit najbolje rezultate pokazuje u očuvanju hrskavice usprkos tome što je primijećena njegova ekstruzija i smanjivanje volumena.

Spencer i sur. ${ }^{45}$ dokazali su da umjetni menisk ima jako dobar učinak u čuvanju hrskavice u prve dvije godine nakon ugradnje, jer od ukupno 23 pacijenta niti kod jednog nisu našli pogoršanje oštećenja hrskavice po Outerbridge skali.

Bulgheroni i suradnici ${ }^{46}$ kod 19 pacijenata ugradili su Actifit. Magnetska rezonancija pokazala je hiperintenzivnost signala implantata i očuvanje hrskavice. $U$ istom radu izvedene su kontrolne artroskopije (second-look) koje su pokazale nepromijenjenu veličinu implantata i dobru integraciju u okolna tkiva u ranijim mjesecima, dok je nepravilna morfologija i smanjivanje volumena implantata opaženo naknadno u 12. i 24. mjesecu.

Monllau i suradnici ${ }^{47}$ su u svom radu dokazali da 70 mjeseci nakon ugradnje Actifit izgubi $0,47 \mathrm{~cm}^{3}$ (sa $1,61 \mathrm{~cm}^{3}$ na $1,14 \mathrm{~cm}^{3}$ ) i dolazi do $2,4 \mathrm{~mm}$ eks- truzije, za razliku od studije Leroya i suradnika ${ }^{48}$ koji su pokazali da nakon 6 godina praćenja ne dolazi do ekstruzije Actifita, ali ipak dolazi do smanjenja njegova volumena.

Faivre i suradnici ${ }^{49}$ istražili su koliko ekstruzija meniska koja nastane nakon puknuća meniska utječe na ekstruziju ugrađenog umjetnog menska. Pratili su 20 pacijenata kroz 12 mjeseci. Analizom pomoću MR-a došli su do zaključka da nema povezanosti između prijeoperacijske ekstruzije meniska i poslijeoperacijske ekstruzije umjetnog meniska, niti progresije oštećenja hrskavice.

Preglednim člankom Shin i suradnici ${ }^{25}$ obuhvatili su 18 istraživanja s pacijentima kojima je ugrađen Actifit. Vrijeme praćenja bilo je 12 do 72 mjeseca. $U$ radu su uspoređivali funkcionalne statuse prema upitnicima Lysholm, IKDC, VAS i Tegner te analize MR-a. Došli su do zaključka da prijeoperacijski i poslijeoperacijski nema značajne razlike u građi i veličini implantata. Uočilo se pogoršanje $u$ oštećenju hrskavice i ekstruziji meniska, ali nasuprot tome, pacijenti su poslijeoperacijski imali značajno funkcionalno poboljšanje i ublažavanje bola.

Coninck i suradnici ${ }^{50}$, prateći pacijente 2 godine radiološki MR-om i klinički upitnicima VAS, KOOS, Lysholm i IKDC, dokazali su da nema pozitivne korelacije između ekstruzije implantata i kliničke slike pacijenata.

Radi preglednosti smo u tablici 3 prikazali rezultate studija koje su koristile samo Actifit i funkcionalne upitnike Tegner, Lysholm i VAS, kao i u našem istraživanju ${ }^{25}$ (tablica 3 ). Pregledom rezultata može se zaključiti da je nakon operacijskog zahvata prema Lysholm, Tegner i VAS upitniku kod svih studija došlo do značajnog poboljšanja. Vrhunski sportaši se rijetko odlučuju na ugradnju umjetnog meniska i ovdje je potreban oprez zbog dužine rehabilitacije i upitnosti definitivnog rezultata. Ipak, Zaffagnini i suradnici ${ }^{51}$ su prikazali primjer vrhunskog nogometaša od 24 godine kome su ugradili umjetni menisk. Pacijent se vratio istoj razini sporta 10 mjeseci nakon operacije i igrao nogomet 3 godine bez dodatnih operacija.

Trenutno ne postoji idealan implantat meniska, međutim, inženjering tkiva meniska brzo se razvija i obećava da će se razviti implantat koji oponaša histološka i biomehanička svojstva prirodnog meniska. Budući implantati meniska mogli bi ići i 
Tablica 3. Pregled vrijednosti upitnika ugradnje umjetnog meniska drugih autora ${ }^{25}$

\begin{tabular}{|c|c|c|c|c|c|c|}
\hline \multirow[b]{2}{*}{ Istraživanje } & \multicolumn{3}{|c|}{ Prije operacije } & \multicolumn{3}{|c|}{ Poslije operacije } \\
\hline & Prosjek & SD & broj pac. & Prosjek & SD & broj pac. \\
\hline \multicolumn{7}{|c|}{ 1. Lysholm } \\
\hline Baynat et al. 2014. & 55.2 & 13.1 & 18 & 94.3 & 14.5 & 18 \\
\hline Bulgheroni et al. 2013. & 66.2 & 14.5 & 20 & 90.5 & 13.4 & 20 \\
\hline Bulgheroni et al. 2015. & 67.0 & 15.7 & 25 & 90.3 & 13.1 & 25 \\
\hline Coninck et al. 2013. & 52.1 & 17.4 & 23 & 76.2 & 20.1 & 23 \\
\hline Martin-Hernandez et al. 2015. & 63.5 & 15.4 & 10 & 84.4 & 14.9 & 10 \\
\hline Spencer et al. 2012. & 56.5 & 35.9 & 11 & 86.6 & 24.2 & 5 \\
\hline Verdonk et al. 2012. & 60.1 & 19.2 & 52 & 80.7 & 19.5 & 52 \\
\hline \multicolumn{7}{|c|}{ 2. Tegner } \\
\hline Bulgheroni et al. 2013. & 3.8 & 2.8 & 20 & 6.0 & 2.1 & 20 \\
\hline Bulgheroni et al. 2015. & 4.0 & 2.6 & 25 & 5.0 & 2.0 & 25 \\
\hline Filardo et al. 2016. & 2.0 & 5.1 & 16 & 3.5 & 3.1 & 16 \\
\hline Kon et al. 2014. & 2.0 & 4.3 & 18 & 3.0 & 3.2 & 18 \\
\hline Spencer et al. 2012. & 3.8 & 2.9 & 11 & 4.4 & 1.9 & 5 \\
\hline \multicolumn{7}{|c|}{ 3. VAS } \\
\hline Bouyamane et al. 2014. & 4.4 & 2.3 & 54 & 7.0 & 2.5 & 54 \\
\hline Bulgheroni et al. 2013. & 3.7 & 2.1 & 20 & 8.0 & 2.3 & 20 \\
\hline Coninck et al. 2013. & 4.5 & 2.2 & 23 & 7.8 & 2.2 & 23 \\
\hline Dhollander et al. 2016. & 4.3 & 2.1 & 44 & 8.0 & 2.6 & 25 \\
\hline Efe et al. 2012. & 5.8 & 2.9 & 10 & 7.9 & 3.1 & 10 \\
\hline Gelber et al. (1) 2015. & 2.8 & 1.1 & 30 & 7.5 & 2.1 & 30 \\
\hline Gelber et al. (2) 2015. & 2.5 & 1.2 & 54 & 7.7 & 1.5 & 54 \\
\hline Martin-Hernandez et al. 2015. & 4.3 & 1.8 & 10 & 8.1 & 1.7 & 10 \\
\hline Schuttler et al. 2015. & 4.9 & 2.0 & 18 & 4.9 & 2.1 & 18 \\
\hline Schuttler et al. 2016. & 4.8 & 2.0 & 18 & 9.0 & 1.4 & 18 \\
\hline Verdonk et al. 2012. & 5.4 & 2.6 & 52 & 7.9 & 2.3 & 52 \\
\hline
\end{tabular}

u smjeru korištenja faktora rasta koji bi stimulirati staničnu proliferaciju i diferencijaciju kako bi se izazvala regeneracija prirodnog meniska ${ }^{49}$.

\section{ZAKLJUČCI}

Nakon ugradnje umjetnog meniska kod našeg malog broja pacijenata, i relativno kratkog praćenja, ustanovili smo bitno poboljšanje funkcionalnog statusa koljena. Značajno je smanjen bol, a svi pacijenti su značajno povećali razinu tjelesne aktivnosti u odnosu na prijeoperacijsko razdoblje nakon meniscektomije. Analizirajući MR nakon operacije, nađen je gubitak morfologije i volumena kao i ekstruzija implantata. Usprkos tome nije došlo do progresije oštećenja hrskavice. Na osnovi navedenog možemo ustvrditi da se djelomični defekti meniska nakon parcijalnih meniscektomi- ja koji uzrokuju preopterećenje hrskavičnog pokrova, a time i bolove, mogu uspješno liječiti umjetnim meniskom građenim od poliuretanskog biorazgradivog nosača. Navedeni presadak prema prvim rezultatima sprječava napredovanje oštećenja hrskavice. Potrebna su daljnja istraživanja s većim brojem pacijenata i dužim vremenom praćenja kako bismo mogli donositi zaključke $s$ većom sigurnošću.

Izjava o sukobu interesa: Autori izjavljuju da ne postoji sukob interesa.

\section{LITERATURA}

1. Englund M, Guermazi A, Lohmander LS. The meniscus in knee osteoarthritis. Rheum Dis Clin North Am 2009;35: 579-590.

2. Englund M, Roos EM, Lohmander LS. Impact of type of meniscal tear on radiographic and symptomatic knee os- 
teoarthritis: a sixteen-year follow up of meniscectomy with matched controls. Arthritis Rheum 2003;48:21782187.

3. Heijink A, Gomoll AH, Madry H, Drobnic M, Filardo G, Espregueira-Mendes J, Van Dijk CN. Biomechanical considerations in the pathogenesis of osteoarthritis of the knee. Knee Surg Sports Traumatol Arthrosc 2012;20:423435.

4. Claes S, Hermie L, Verdonk R. Is osteoarthritis an inevitable consequence of anterior cruciate ligament reconstruction? A meta-analysis. Knee Surg Sports Traumatol Arthrosc 2013;21:1967-1976.

5. Pećina $M$, Orlić $D$. Gonartroze nakon meniscektomije. Acta orthop Jugosl 1975; 6/2-3:377-384.

6. Pećina M. Koljeno - Primjenjena biomehanika. JUMENA, Zagreb: 1982.

7. Orlić $\mathrm{D}$, Pećina $\mathrm{M}$, Antičević $\mathrm{D}$. Uzroci i učestalost nastanka gonartroza nakon meniscektomija 1984; ŠMO. 21/9-12:302-304.

8. Pećina $M$, Hašpl M. Koljeno i potkoljenica. U: Pećina M. i sur. Ortopedija. Zagreb: Naklada Ljevak, 2004; 341-50.

9. Jelić M, Vlaić J, Josipović M, Serdar J. Ozljede meniska. U:Pećina M. i sur. Sportska medicina. Zagreb: Medicinska naklada, 2019;156-174.

10. Levy IM, Torzilli PA, Warren RF. The effect of medial meniscectomy on anterior-posterior motion of the knee. J Bone Jt Surg Am 1982;64:883-888.

11. Levy IM, Torzilli PA, Gould JD, Warren RF. The effect of lateral meniscectomy on motion of the knee. J Bone Jt Surg Am 1989;71:401-406.

12. Kurosawa $\mathrm{H}$, Fukubayashi $\mathrm{T}$, Nakajima $\mathrm{H}$ Load-bearing mode of the knee joint: physical behavior of the knee joint with or without menisci. Clin Orthop 1980;149:283290.

13. Atmaca $\mathrm{H}$ et al. Changes in the loading of tibial articular cartilage following medial meniscectomy: a finite element analysis study. Knee Surg Sports Traumatol Arthrosc 2013;21:2667-2673.

14. Allaire R, Muriuki M, Gilbertson L, Harner CD. Biomechanical Consequences of a Tear of the Posterior Root of the Medial Meniscus: Similar to Total Meniscectomy. J Bone Joint Surg Am 2008;90:1922-1931.

15. Caiqi Xu, Jinzhong Zhao. A meta-analysis comparing meniscal repair with meniscectomy in the treatment of meniscal tears: the more meniscus, the better outcome? Knee Surgery, Sports Traumatology, Arthroscopy 2015; 23:164-170.

16. Kang DG, Park YJ, Yu JH, Oh JB, Lee DY. A Systematic Review and Meta-Analysis of Arthroscopic Meniscus Repair in Young Patients: Comparison of All-Inside and InsideOut Suture Techniques. Knee Surg Relat Res 2019;31:111.

17. Scott Paxton E, Stock MV, Brophy RH. Meniscal Repair Versus Partial Meniscectomy: A Systematic Review Comparing Reoperation Rates and Clinical Outcomes. Arthroscopy 2011;27:1275-1288.

18. Tršek $D$, Hašpl M, Starčević D, Tabak T. Current concept of the meniscal repair. Medicina fluminensis 2015;51: 154-174.

19. Dangelmajer S, Familiari F, Simonetta R, Kaymakoglu M, Meniscal GH. Transplants and Scaffolds: A Systematic Review of the Literature. Knee Surg Relat Res 2017;29:310.
20. Verdonk PC, Demurie A, Almqvist KF, Veys EM, Verbruggen $\mathrm{G}$, Verdonk $\mathrm{R}$ Transplantation of viable meniscal allograft. Surgical technique. J Bone Joint Surg Am 2006;88:109-118.

21. Monllau JC, Gelber PE, Abat F et al. Outcome after partial medial meniscus substitution with the collagen meniscal implant at a minimum of 10 years' follow-up. Arthroscopy 2011;27:933-943.

22. Bulgheroni P, Murena L, Ratti C, Bulgheroni E, Ronga M, Cherubino P. Follow-up of collagen meniscus implant patients: clinical, radiological, and magnetic resonance imaging results at 5years. Knee 2010;17:224-229.

23. Houck DA, Kraeutler MJ, Belk JW, McCarty EC, Bravman JT. Similar clinical outcomes following collagen or polyurethane meniscal scaffold implantation: a systematic review. Knee Surg Sports Traumatol Arthrosc 2018;26: 2259-2269.

24. Kon E1, Filardo G, Zaffagnini S, Di Martino A, Di Matteo B, Marcheggiani Muccioli GM, Busacca M, Marcacci M. Biodegradable polyurethane meniscal scaffold for isolated partial lesions or as combined procedure for knees with multiple comorbidities: clinical results at 2 years. Knee Surg Sports Traumatol Arthrosc 2014;22:128-34.

25. Shin YS, Lee HN, Sim HB, Kim HJ, Lee DH3. Polyurethane meniscal scaffolds lead to better clinical outcomes but worse articular cartilage status and greater absolute meniscal extrusion. Knee Surg Sports Traumatol Arthrosc. 2018;26:2227-2238.

26. Schüttler KF, Pöttgen S, Getgood A et al. Improvement in outcomes after implantation of a novel polyurethane meniscal scaffold for the treatment of medial meniscus deficiency. Knee Surg Sports Traumatol Arthrosc 2015;23:1929-1935.

27. Barber FA, Herbert MA. Meniscal repair devices. Arthroscopy 2000;16:613-8.

28. Chang $\mathrm{HC}$ at al. Biomechanical evaluation of meniscal repair systems: a comparison of the Meniscal Viper Repair System, the vertical mattress FasT-Fix Device, and vertical mattress ethibond sutures. Am J Sports Med 2005;33:1846-52.

29. Hardeman F, Corten K, Mylle M, Van Herck B, Verdonk R, Verdonk $\mathrm{P}$, Bellemans J. What is the best way to fix a polyurethane meniscal scaffold? A biomechanical evaluation of different fixation modes. Knee Surg Sports Traumatol Arthrosc 2015;23:59-64.

30. Genovese E1, Angeretti MG, Ronga M, Leonardi A, Novario R, Callegari L, Fugazzola C. Follow-up of collagen meniscus implants by MRI. Radiol Med 2007;112:103648.

31. Wilcoxon F. Individual comparisons by ranking methods. Biometrics Bulletin 1945;1:80-83.

32. R Core Team. R. A Language and Environment for Statistical Computing. Beč: R Foundation for Statistical Computing, 2019.

33. Krych AJ, Reardon P, Sousa P, Levy BA, Dahm DL, Stuart MJ. Clinical Outcomes After Revision Meniscus Repair. Arthroscopy 2016;32:1831-7.

34. Voloshin I, Schmitz MA, Adams MJ, DeHaven KE. Results of repeat meniscal repair. Am J Sports Med. 2003;31: 874-80.

35. Imade $\mathrm{S}$, Kumahashi $\mathrm{N}$, Kuwata $\mathrm{S}$, Kadowaki $\mathrm{M}$, Ito $\mathrm{S}$, Uchio Y. Clinical outcomes of revision meniscal repair: a case series. Am J Sports Med. 2014;42:350-7. 
36. Pujol N, Barbier O, Boisrenoult P, Beaufils P. Amount of meniscal resection after failed meniscal repair. Am J Sports Med. 2011;39:1648-52.

37. Fuchs $A$, Kloos F, Bode $G$, Izadpanah $K$, Südkamp NP, Feucht MJ. Isolated revision meniscal repair - failure rates, clinical outcome, and patient satisfaction. BMC Musculoskelet Disord. 2018;21:19:446.

38. Fetzer GB, Spindler KP, Amendola A, Andrish JT, Bergfeld JA, Dunn WR, Flanigan DC, Jones M, Kaeding CC, Marx RG, Matava MJ, McCarty EC, Parker RD, Wolcott M, Vidal $A$, Wolf BR, Wright RW. Potential market for new meniscus repair strategies: evaluation of the MOON cohort. J Knee Surg. 2009;22:180-6.

39. Liu C, Toma IC, Mastrogiacomo M, Krettek C, von Lewinski G, Jagodzinski M. Meniscus reconstruction: today's achievements and premises for the future. Arch Orthop Trauma Surg. 2013;133:95-109.

40. Myers P, Tudor F Meniscal allograft transplantation: how should we be doing it? A systematic review. Arthroscopy 2015;31:911-925.

41. Pollard ME, Kang $Q$, Berg EE. Radiographic sizing for meniscal transplantation. Arthroscopy 1995;11:684-687.

42. Stevenson C, Mahmoud A, Tudor F, Myers P. Meniscal allograft transplantation: undersizing grafts can lead to increased rates of clinical and mechanical failure. Knee Surgery, Sports Traumatology, Arthroscopy 2019;27: 1900-1907.

43. Gonzalez-Lucena G, Gelber PE, Pelfort X, Tey M, Monllau JC. Meniscal allograft transplantation without bone blocks: a 5- to 8-year follow-up of 33 patients. Arthroscopy 2010; 26:1633-40.

44. Roumazeille $\mathrm{T}$, Klouche $\mathrm{S}$, Rousselin B, Bongiorno $\mathrm{V}$, Graveleau N, Billot N, Hardy P. Arthroscopic meniscal al- lograft transplantation with two tibia tunnels without bone plugs: evaluation of healing on MR arthrography and functional outcomes. Knee Surg Sports Traumatol Arthrosc 2015; 23:264-9.

45. Spencer SJ, Saithna A, Carmont MR, Dhillon MS, Thompson P, Spalding T. Meniscal scaffolds: early experience and review of the literature. Knee. 2012;19:760-5.

46. Bulgheroni $P$, Bulgheroni $E$, Regazzola $G$, Mazzola C. Polyurethane scaffold for the treatment of partial meniscal tears. Clinical results with a minimum two-year follow-up. Joints 2013;1:161-166.

47. Monllau JC, Poggioli F, Erquicia J, Ramírez E, Pelfort X, Gelber P, Torres-Claramunt R. Magnetic Resonance Imaging and Functional Outcomes After a Polyurethane Meniscal Scaffold Implantation: Minimum 5-Year Followup. Arthroscopy 2018;34:1621-1627.

48. Leroy A, Beaufils P, Faivre B, Steltzlen C, Boisrenoult P, Pujol N. Actifit ${ }^{\circledast}$ polyurethane meniscal scaffold: MRI and functional outcomes after a minimum follow-up of 5 years. Orthop Traumatol Surg Res. 2017;103:609-614.

49. Faivre $B$, Bouyarmane $H$, Lonjon $G$, Boisrenoult $P$, Pujol $N$, Beaufils P. Actifit ${ }^{\circledast}$ scaffold implantation: Influence of preoperative meniscal extrusion on morphological and clinical outcomes. Orthop Traumatol Surg Res. 2015; 101:703-8.

50. De Coninck T, Huysse W, Willemot L, Verdonk R, Verstraete $\mathrm{K}$, Verdonk P. Two-year follow-up study on clinical and radiological outcomes of polyurethane meniscal scaffolds. Am J Sports Med. 2013;41:64-72.

51. Zaffagnini S, Marcheggiani Muccioli GM, Grassi A, Bonanzinga T, Filardo $G$, Canales Passalacqua A, Marcacci $M$. Arthroscopic lateral collagen meniscus implant in a professional soccer player. Knee Surg Sports Traumatol Arthrosc 2011;19:1740-3. 